Reprod. Nutr. Dévelop., 1988, 28 (1), 109-110.

\title{
Evolution du poids du contenu du réticulo-rumen chez les vaches laitières au cours des deux premiers mois de la lactation.
}

B. RÉMOND

Laboratoire de la Lactation,

I.N.R.A., Theix, 63122 Ceyrat, France.

Summary. In dairy cows the weight of the reticulo-ruminal content increases during the first two months of lactation similarly to feed intake. The increase is about $3 \mathrm{~kg} / \mathrm{kg}$ dry matter intake.

Chez les bovins adultes, le poids du contenu digestif est élevé et variable (11 à $20 \%$ du poids vif selon Béranger et Robelin, 1978) et constitué pour près des trois quarts par le contenu du réticulo-rumen. Nous avons étudié les variations pondérales de ce dernier au début de la lactation de façon à pouvoir mieux estimer la diminution systématique de masse corporelle des vaches laitières pendant cette période.

Matériel et méthodes. Nous avons utilisé 131 pesées de contenus de réticulorumen, effectuées dans 7 essais sur 25 vaches au total (1 à 6 par essai), au cours des 66 premiers jours de la lactation. Les animaux, de type Pie Noir, portaient une large canule du rumen (11 à $12 \mathrm{~cm}$ de diamètre). Leur numéro de lactation, leur production laitière journalière maximale et leur poids vif après vêlage étaient en moyenne respectivement de $4,2,28,0 \mathrm{~kg}$ et $610 \mathrm{~kg}$. Dans tous les essais, la ration était de composition à peu près constante et constituée en moyenne de $70 \%$ d'ensilage de maïs et de $30 \%$ d'aliment concentré dans la matière sèche (MS) ; ses teneurs en matières azotées totales et en cellulose brute étaient respectivement de $16,1 \%$ et $15,7 \%$. Elle était offerte à volonté, sauf à l'occasion de 12 mesures en $1^{\text {re }}$ semaine de lactation, pour lesquelles la ration n'était cependant que modérément limitée (102 g de MS par $\mathrm{kg}$ de poids métabolique). Les contenus de réticulo-rumen étaient collectés dans des bacs étanches par vidage de la phase solide à la main, et de la phase liquide avec une pompe à vide. Les vidages avaient lieu de 3 à $5 \mathrm{~h}$ après la distribution des aliments du matin. Les vaches étaient pesées au cours de la $1^{r e}$ semaine de lactation. Les quantités ingérées prises en considération ont été celles enregistrées la veille du vidage. Pour le dépouillement des résultats, nous avons réparti les données en 5 classes selon le délai de la mesure après le vêlage : 0 à 10,11 à 20, 21 à 30,31 à 50,51 à 66 jours et, le cas échéant, avons fait, pour chaque vache, les moyennes des différentes mesures effectuées au cours de la même période, ce qui a ramené le nombre de données à 105.

Résultats. Après le vêlage, le poids du contenu du réticulo-rumen s'est accru selon un modèle de type exponentiel, de façon très semblable à la quantité d'aliments ingérée (fig. 1), ce qui suggère une liaison fonctionnelle entre ces 2 variables; son accroissement entre le début de la lactation ( $5^{\mathrm{e}}$ jour) et soit la fin du $1^{\text {er }}$ mois $\left(30^{\mathrm{e}}\right.$ jour $)$, soit celle du $2^{\mathrm{e}}$ mois $\left(60^{\mathrm{e}}\right.$ jour) de lactation, par kg supplémentaire de MS ingérée pendant la même période, a été pratiquement identique : respectivement 2,85 et $2,95 \mathrm{~kg}$. Ces coefficients sont proches des pentes des axes principaux reliant ces 2 variables pour l'ensemble des 105 données 13,1 ou $3,3 \mathrm{~kg}$ de poids de contenu de réticulo-rumen par $\mathrm{kg}$ de MS ingérée, selon qu'on tient compte, ou non, du poids des animaux; fig. 2). Dans le premier stade de lactation, l'augmentation de poids du contenu du réticulo-rumen par $\mathrm{kg}$ d'accroisse-

Reproduction, Nutrition, Développement, $n^{\circ}$ 1-88. -8 
ment des quantités ingérées est légèrement inférieure à celle dans les autres stades $(2,3 \mathrm{~kg}$ contre $3,3 \mathrm{~kg}$ en moyenne), mais cette différence n'est pas significative.

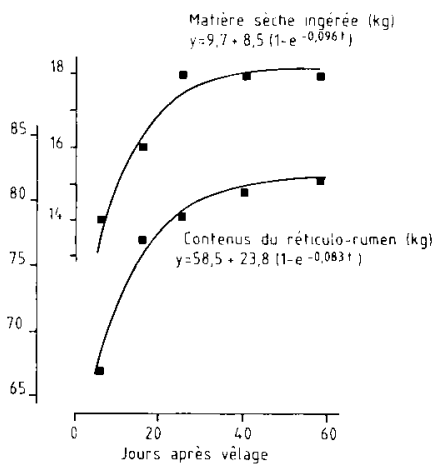

FIG. 1. - Evolution des quantités de matière sèche ingérée et de contenus du réticulo-rumen pendant les 2 premiers mois de lactation.

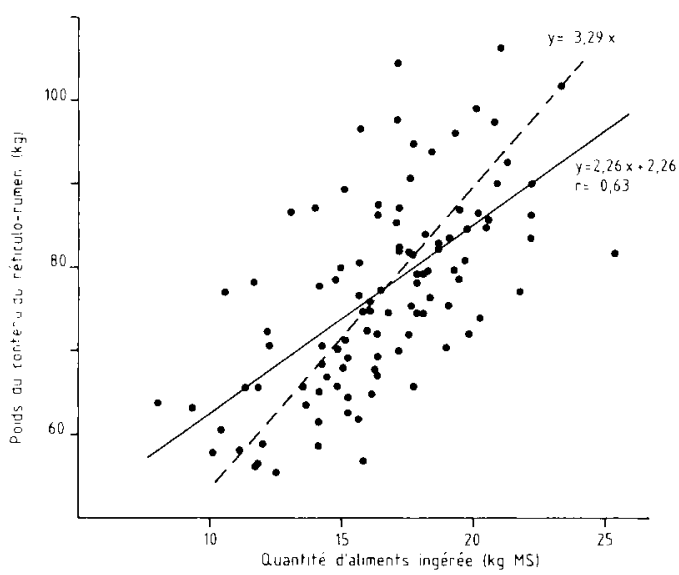

FIG. 2. - Liaison entre la quantité d'aliment ingérée et le poids du contenu du réticulo-rumen (105 données).

En conclusion, dans les conditions zootechniques proches de celles de cette étude, on peut estimer que le poids du contenu du réticulo-rumen mesuré après le repas du matin s'accroît, en début de lactation, d'environ 3,0 kg par kg supplémentaire de MS d'aliment ingérée.

Remerciements. - Je remercie vivement R. Fournier et $\mathrm{E}$. Girard qui ont effectué la quasitotalité des vidages, et $Y$. Chilliard, M. Doreau, M. Journet et $R$. Vérité qui ont mis leurs résultats à ma disposition.

Béranger C., Robelin J., 1978. Ann. Zootech., 27, 639-645. 